\title{
Changes in blood flow, portal pressure and shunting during the development of cirrhosis in response to beta-blockade
}

\author{
M McLAREN, S BRAYE, J FLEMING, S KARRAN, AND I TAYLOR \\ From the University Surgical Unit and Dept.. of Nuclear Medicine, Southampton.
}

SUMMARY An experimental model of cirrhosis was developed in the rat to assess the effect of disease and pharmacological manipulation on blood flow, shunting and portal pressure. With progression in the severity of histological cirrhosis there was a steady fall in effective liver blood flow as measured with radioisotope labelled colloid. This corresponded to a rise in portal pressure and shunting with a close correlation between the two $(r=0 \cdot 7, p<0 \cdot 01)$. In control animals and when portal hypertension was caused by extrahepatic obstruction, beta-blockade with propranolol, but not selective beta 2 blockade, significantly decreased liver blood flow. With cirrhosis there was a variable response to propranolol depending on the histological severity of disease, the height of portal pressure and degree of shunting. There is a possibility therefore that a potential may exist for lowering portal pressure by manipulating intrahepatic shunting.

Considerable enthusiasm exists for attempting pharmacological reduction of raised portal venous pressure in patients with cirrhosis and portal hypertension. The rationale for this therapeutic approach being that by a lowering of such pressure the risk of variceal bleeding, and hence life threatening complications, may become less without the additional problems that arise with therapeutic surgical shunting. Most attention has been concentrated on the effects of beta adrenergic blockade ${ }^{1.5}$ with initial studies using propranolol. ${ }^{13}$

The mechanisms whereby pressure may be reduced by such drug therapy and the effects which this could have on the functional blood flow of the liver is, however, still far from clear. ${ }^{1.5}$ The major local haemodynamic factors involved in the pathophysiological equation of cirrhosis are the portal venous pressure itself, the dual nature of the hepatic arterial and portal venous blood supply, together with the extent of any intra or extra hepatic shunting.

The aims of the present study were to evaluate

\footnotetext{
Address for correspondence: Professor I Taylor, University Surgical Unit, Faculty of Medicine, F Level, Centre Block, Southampton General Hospital, Tremona Road, Southampton SO1 6HU.

Received for publication 30 October 1986.
}

the relationship of these parameters with the development of cirrhosis in an experimental animal model. In addition an assessment was made of acute changes in hepatic blood flow as a result of drug therapy with both propranolol (a non-specific betablocker) and B2 118551 (a beta 2-blocker).

\section{Methods}

EXPERIMENTAL CIRRHOSIS

Male Wistar rats, with an initial weight of $150 \mathrm{~g}$ were used (Charles Rivers Laboratories). Free access to a stock diet was allowed. After segregation each rat received either ordinary drinking water or only water containing dissolved sodium phenobarbitone bp at a concentration of $35 \mathrm{mg} / \mathrm{ml}$. Control data were obtained from representative samples of these two groups - that is, those rats with or without previous enzyme induction. Experimental cirrhosis was then produced using one of two hepatotoxins with different dosing regimes.

Carbon tetrachloride was administered on a weekly basis through an orogastric tube using a recently described modification of an established experimental model ${ }^{6}$ to rats receiving pheno- 
barbitone. A separate group were given dimethylnitrosamine, delivered in a similar physical manner but on a strict eight week cycle. ${ }^{78}$

Both agents are accepted as being capable of producing an experimental rat model of cirrhosis using these methods. A further group of weanling rats underwent an operation when two weeks old to reproduce a model of extrahepatic portal hypertension without the liver cell damage associated with cirrhosis. The technique used was based on an established method.$^{89}$ Under ether anaesthesia and through a midline incision the extrahepatic portal vein was isolated. A 6 '0 prolene ligature was tied around the portal vein to include a blunted 27 gauge needle so that when withdrawn the portal vein was stenosed but not occluded. This segment was proximal to the bifurcation of the left and right branches but distal to the prepyloric vein. After recovery from this surgery investigations were delayed for a minimum of three months.

With the cirrhotic rats investigations were undertaken either at the onset of established ascites or after 12 weeks carbon tetrachloride and eight weeks of dimethylnitrosamine respectively.

Histological assessment was undertaken to confirm the presence of and to designate a grade of severity from I to III for each liver showing cirrhosis. This grade was derived from a comparison of seven differing parameters as judged from separate slides stained with either haematoxylin and eosin or 'untoned reticulin'. These were related to the degree of fibrosis, regeneration, necrosis, inflammation, cholestasis, Kupffer cell hyperplasia, and pigment accumulation. All these parameters are a feature of cirrhosis produced using the hepatotoxins used in this study. The more important features, however, of fibrosis and regeneration were considered of major importance. In addition biochemical tests were undertaken to assess the value of such a grading as being a true reflection of disease progression in terms of function.

Assays were carried out on both plasma and homogenised samples of liver tissue. The synthetic capacity of the liver for both normal and abnormal products was reflected by measurement of plasma and liver tissue protein, albumin and sialic acid. Cellular damage was monitored by recording the plasma alanine transaminase activity.

MEASUREMENT OF LIVER BLOOD FLOW

Blood flow to the liver was measured by analysis of sequential images recorded by a gamma camera after the intravenous injection of radioisotope labelled Technetium sulphur colloid. The theoretical basis of such dynamic liver scanning has been described in detail previously. ${ }^{11}$ In practice, once anaesthetised with fentanyl-fluanisone (Hypnorm, Jensen) each rat was taped supine beneath a pinhole collimator fitted to a Nuclear Enterprises Mk III gamma camera; this in turn being linked to a Medical Data Systems International on-line computer. After a bolus intravenous injection of Technetium - 99 sulphur colloid (Technecoll, Mallinckrodt) with a maximum volume of $0.2 \mathrm{ml}$, image acquisition of 90 frames of 5 second duration was performed. At the conclusion of this dynamic phase a 20 second whole body static image was recorded using a parallel hole collimator.

From subsequent analysis ${ }^{111}$ a clearance constant rate for the injected colloid, and percentage uptake in the liver were derived. With a knowledge of the blood volume, derived from the whole body weight, ${ }^{12}$ and the liver mass, recorded at the completion of studies, an estimate of liver blood flow in millilitres per gram of liver per minute can be made. During blood flow recordings ECG electrodes were attached to the precordium for monitoring the heart rate.

PORTAL PRESSURE AND PORTAL SYSTEMIC SHUNTING MEASUREMENT

After blood flow recordings each rat received a second, but identical anaesthetic at 48 hours, and underwent a laparotomy. Through a midline incision the terminal small bowel was reflected to the animal's left and an 18 gauge portex catheter introduced in a retrograde fashion up to the anterior mesenteric vein to lie within the portal vein. By connecting this to a conventional venous manometer primed with normal saline portal pressure was recorded. After such measurements the same catheter was used to inject radiolabelled microspheres (15 $\mu$ Co57 Nen-Trac microspheres, New England Nuclear). The technique used was founded on previous studies. ${ }^{13}$ The microspheres were agitated for two minutes using a whirlimixer and approximately $0.05 \mathrm{ml}$ drawn into a graduated $1 \mathrm{ml}$ syringe. This was then connected to the portex tubing and the contained microspheres injected over 10 seconds, followed by $0.2 \mathrm{ml}$. normal saline over 20 seconds to flush the tube. After 20 minutes the rat was killed by exsangination via an aortic puncture. The lungs and liver once weighed were subsequently counted in a $\mathrm{J}$ and $\mathrm{P}$ Nucleonics gamma scintillation counter.

The percentage of portal systemic shunting was then calculated using a simple equation which provides a relative index, thereby obviating the need to measure precise quantities of microspheres/ radioactivity injected: \% $\mathrm{PSS}=$ net lung radioactivity/net (lung+liver) radioactivity $\times 100$.

\section{DRUGS}

Based on a careful assessment of the relevant pharmacodynamics and pharmacokinetics the route 
of administration chosen for propranolol and by inference B2 118551 was oral. Similarly the most appropriate dose to produce a pharmacological effect was selected which in the case of propranolol was confirmed experimentally by demonstrating a significant reduction in heart rate.

\section{STATISTICAL ANALYSIS}

Data have been presented as means \pm SEM. Statistical comparisons have been made using a standard Student's $t$ test. With repeat blood flow measurement a difference of $>10 \%$ was considered significant as this was in excess of any error intrinsic consequent on the technique of blood flow measurement used."

\section{Results}

There were 26 rats with grade I cirrhosis, 34 with grade II, and 36 with grade III. There were 13 rats with extrahepatic portal hypertension. In the group of rats with cirrhosis 36 underwent blood flow studies before and after propanolol.

\section{BIOCHEMICAL CHANGES (TABLE 1)}

There were no significant differences in the biochemical tests between those control rats who had or had not received previous enzyme induction. There were consistent changes in the biochemical parameters used to assess disease severity matching the grading system based on histology alone.

PORTAL PRESSURE (TABLE 2)

The mean portal pressure in the control rats was $9 \mathrm{~cm}$ saline. With cirrhosis there was an increase in the

Table 1 Biochemical results (mean $\pm S E M$ )

\begin{tabular}{|c|c|c|c|c|}
\hline & \multirow[b]{2}{*}{ Controls } & \multicolumn{3}{|l|}{$\begin{array}{l}\text { Cirrhosis } \\
\text { Grade }\end{array}$} \\
\hline & & $I$ & II & III \\
\hline $\mathrm{n}=$ & 30 & 26 & 34 & 36 \\
\hline \multicolumn{5}{|l|}{ Plasma } \\
\hline Protein & $55 \cdot 1$ & $38 \cdot 4^{*}$ & $41 \cdot 0$ & $31 \cdot 6$ \\
\hline $\mathrm{mg} / \mathrm{ml}$ & $\pm 2 \cdot 1$ & $\pm 1 \cdot 8$ & $\pm 2 \cdot 1$ & $\pm 2 \cdot 0$ \\
\hline Albumin & $41 \cdot 4$ & $29 \cdot 5^{*}$ & $26 \cdot 7$ & $21 \cdot 7$ \\
\hline $\mathrm{mg} / \mathrm{ml}$ & \pm 0.4 & $\pm 1 \cdot 8$ & $\pm 1 \cdot 5$ & \pm 1.6 \\
\hline \multicolumn{5}{|l|}{ Alanine } \\
\hline transaminase & 52 & $99^{*}$ & 109 & 120 \\
\hline IU & \pm 2 & \pm 10 & \pm 8 & \pm 15 \\
\hline \multicolumn{5}{|l|}{ Liver } \\
\hline \multicolumn{5}{|l|}{ Protein } \\
\hline \multirow[t]{2}{*}{$\mathrm{mg} / \mathrm{ml}$} & $103 \cdot 5$ & $100 \cdot 9$ & $103 \cdot 7$ & $99 \cdot 2$ \\
\hline & $\pm 3 \cdot 6$ & $\pm 4 \cdot 5$ & $\pm 4 \cdot 2$ & \pm 6.0 \\
\hline \multirow[t]{2}{*}{$\mathrm{mg} / \mathrm{g}$} & $20 \cdot 9$ & $20 \cdot 15$ & $20 \cdot 8$ & $19 \cdot 8$ \\
\hline & \pm 0.76 & \pm 0.9 & \pm 0.9 & $\pm 1 \cdot 2$ \\
\hline Sialic acid & 3.05 & $4 \cdot 67^{*}$ & $5 \cdot 15$ & $6 \cdot 0$ \\
\hline $\mathrm{pg} / \mathrm{mg}$ & $\pm 0 \cdot 14$ & $\pm 0 \cdot 21$ & \pm 0.34 & \pm 0.5 \\
\hline
\end{tabular}

Table 2 Portal pressure, portal systemic shunting and liver blood flow in the groups (mean $\pm S E M$ )

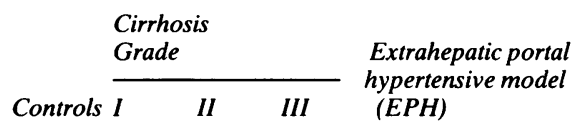

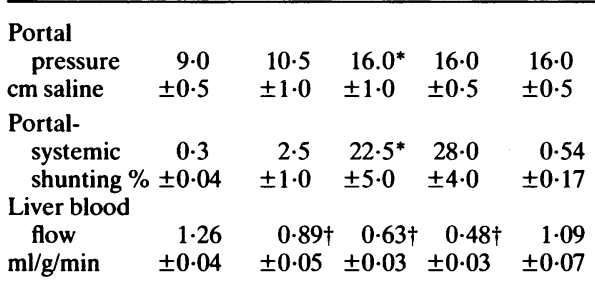

${ }^{*} \mathrm{p}<0 \cdot 01$. Control V grade II; $\nmid \mathrm{p}<0 \cdot 01$

level of portal pressure. The significant increase occurred between grades I and II, with no difference between grades II and III. Extrahepatic portal hypertension of a similar degree was also achieved.

PORTAL SYSTEMIC SHUNTING

The mean percentage shunting in the control group was very low at $0.3 \%$. There was an increase with disease progression up to a mean of $28.0 \%$ in grade III. Again the significant increase occurred between grades I and II, with the difference between grades II and III not reaching statistical significance. No increase occurred when the portal hypertension was due to an extrahepatic block.

There was a close correlation between the level of raised portal pressure and an increase in the degree of shunting. $(r=0.7$ with $p<0.01)$.

LIVER BLOOD FLOW (TABLE 2)

With progressively severe cirrhosis there was a steady fall in the recorded liver blood flow from a mean of $1.26 \mathrm{ml} / \mathrm{g} / \mathrm{min}$ in control rats to $0.48 \mathrm{ml} / \mathrm{g} / \mathrm{min}$ in grade III. Overall there was a poor negative correlation between increased portal pressure and a reduction in blood flow $(r=-0.04$ with $p<0 \cdot 05)$. There was no correlation between the degree of shunting and any blood flow changes.

EFFECT OF BETA BLOCKADE (TABLES 3 AND 4) In the control rats propranolol resulted in a statistically significant fall in blood flow. There was a small reduction produced by beta 2 blockade alone using B2 118551 but this did not reach statistical significance.

In cirrhotic rats propranolol produced an increased measured flow of greater than $10 \%$ in 20 rats with a decreased flow of greater than $10 \%$ in 16 rats.

There were highly significant differences in the 
Table 3 Effect of drugs on liver blood flow ( $\mathrm{ml} / \mathrm{g} / \mathrm{min})$

\begin{tabular}{lccc}
\hline Controls & $\begin{array}{l}\text { Before } \\
10 \mathrm{mg} / \mathrm{kg} \text { Propranolol }\end{array}$ & After & \\
\hline $\begin{array}{l}\text { Normal } \\
\mathrm{n}=10\end{array}$ & 1.25 & 0.99 & $\mathrm{p}<0.01$ \\
$\begin{array}{l}\text { Prior enzyme induction } \\
\mathrm{n}=10\end{array}$ & 1.26 & 0.89 & $\mathrm{p}<0.01$ \\
$\begin{array}{l}\text { EPH } \\
\mathrm{n}=12\end{array}$ & 1.09 & 0.89 & $\mathrm{p}<0.05$ \\
$\begin{array}{l}\text { Controls } \\
\text { Normal } \\
\mathrm{n}=10\end{array}$ & $10 \mathrm{mg} / \mathrm{kg} \mathrm{B} 2 \mathrm{118551}$ & & \\
$\begin{array}{l}\text { Prior enzyme induction } \\
\mathrm{n}=10\end{array}$ & 1.25 & 1.21 & $\mathrm{NS}$ \\
$\begin{array}{l}\text { EPH } \\
\mathrm{n}=12\end{array}$ & 1.26 & 1.17 & $\mathrm{NS}$ \\
\hline
\end{tabular}

Table 4 Significant parameters which in those cirrhotic rats demonstrated a differing response to propranolol

\begin{tabular}{llccl}
\hline & & $\begin{array}{l}\text { Increased flow } \\
\text { after propranolol }\end{array}$ & $\begin{array}{l}\text { Decreased flow } \\
\text { after propranolol }\end{array}$ \\
\hline $\mathrm{n}=$ & & 20 & 16 & \\
Grade of & I & - & 4 & \\
\multicolumn{1}{c}{ cirrhosis } & II & 8 & 5 & \\
& III & 12 & 7 & \\
Portal pressure & 16.5 & 13.0 & $\mathrm{p}<0.001$ \\
& & \pm 0.5 & \pm 1.0 & \\
Shunting & 25.0 & 5.5 & $\mathrm{p}<0.001$ \\
& & \pm 4.0 & \pm 2.5 & \\
\hline
\end{tabular}

$\mathrm{n}=$ number of animals investigated.

values represent mean \pm SEM.

disease severity, level of portal pressure and degree of shunting in these two groups of cirrhotic rats.

\section{Discussion}

Within the limits of the experimental techniques used the majority of portal systemic shunting measured after the portal injection of microspheres in the cirrhotic rats was intrahepatic. This conclusion arises from the comparative values of shunting in the extrahepatic portal hypertensive rats without liver damage whose portal pressures were raised to very similar levels. A close correlation might be anticipated between the level of portal pressure and the degree of extrahepatic portal systemic shunting but the demonstration of a good correlation between such pressure and intrahepatic venous shunting introduces an interesting question with regard to the pathogenesis of the latter. The presence of intrahepatic venous shunts from portal vein to both central and other portal tributaries are considered to arise from both bridging fibrosis and the loss of cell plate alignment as repair runs parallel with necrosis in the cirrhotic process. ${ }^{14}$ Although showing a good correlation for the overall group of rats with cirrhosis the data shown as a summary in Table 2 indicate that the significant rise in portal pressure and shunting occurs between grade I and grade II cirrhosis. In grade III there is no further increase in the level of portal pressure but, although not statistically significant, there was a trend towards a further increase in shunting. If it is accepted that the majority of shunting measured was intrahepatic then this suggests portal pressure acts as a stimulus to divert more blood through these potentials pathways. Similarly, as an extension of this argument, it is conceivable that by manipulating intrahepatic shunting an effect on portal pressure could be produced.

The progressive fall in measured blood flow using radio-labelled colloid relates to several factors. ${ }^{15}$ In addition to reflecting any actual changes in flow there are certain aspects which must be considered when interpreting results. The technique relies on the extraction/isolation of colloid by the Kupffer cells lining the liver sinusoids. To reflect vascular flow, blood laden with colloid must perfuse sinusoids. These in turn need to be lined by functioning Kupffer cells. The liver receives a dual blood supply with the relative proportions of arterial and venous components altering as disease progresses and intrahepatic shunts develop within both territories. ${ }^{14}$ Blood flowing through such shunts will fail to perfuse sinusoids and therefore avoid exposure to Kupffer cells. In addition to this reduction in functional intrahepatic perfusion there is a redistribution of colloid uptake; principally to the spleen and other potential reticuloendothelial sites such as the bone marrow. This arises as a consequence of any qualitative or quantitative impairment to Kupffer cells and the presence of an actual increase in functional splenic activity. The lack of correlation between one type of shunting and blood flow changes reflects these various factors.

When giving adrenoreceptor blocking drugs to patients with raised portal pressure most authors attribute any fall in this pressure to a reduction of cardiac output through beta-1-blockade and splanchnic flow as a sequel to beta-2-blockade; ${ }^{1-5}$ with changes to liver blood flow being secondary phenomena. The question of specific intra-hepatic effect has, however, received little attention. In this study there may be evidence to support such a possibility. In those rats with histologically more severe cirrhosis, higher portal pressures and increased shunting the administration of propranolol led to an increased functional perfusion of sinusoids. This could have arisen because either more blood was actually exposed to Kupffer cells, the same amount 
was exposed for a longer time or there was an increase in reticuloendothelial extraction efficiency. This latter possibility would seem unlikely as no direct effect of beta-blockade on Kupffer cells has been shown.

The data from control rats suggest that the reduction in measured liver blood flow was predominantly caused by beta-1-blockade; the effect of beta2-blockade alone being insufficient to bring about significant reductions. In those cirrhotic rats with higher pressures and shunting the resistance to portal venous flow would also be higher, together with a greater arterial component flow. A reduction of cardiac output will reduce the hepatic arterial pressure. Hepatic arterial vasodilation, already near maximal, is mediated by beta-2-receptors. A blockade of the latter combined with the reduced cardiac output would have the reciprocal effect of reducing portal venous resistance, hence pressure. This would reduce intrahepatic portal systemic shunting and lead to increased perfusion of sinusoids. Although the sum total of volume input to the liver via the hepatic artery and portal vein may be reduced, the functional sinusoidal perfusion measured using Technecoll may actually increase.

The implications if such a mechanism exists are two-fold. Firstly there may not be an anticipated deleterious effect on functional liver blood flow using beta-blockers. More importantly, though, the potential may well be present to manipulate intrahepatic shunting and hence reduce portal pressure with other drugs such as vasodilators.

We are extremely grateful to the Wellcome Foundation for funding these studies. Mr T Richards and staff provided expert care of all animals involved.

\section{References}

1 Lebrec D, Poynard T, Bernuau J, et al. A randomized controlled study of propranolol for the prevention of recurrent gastrointestinal bleeding in patients with cirrhosis: a final report. Hepatology 1984 ; 4: 355-8.
2 Westaby D, Melia WM, MacDougall BRD, Hegarty JE, Gimson AE, Williams R. B1 selective adrenoreceptor blockade for the long term management of variceal bleeding. A prospective randomised trial to compare oral metoprolol with injection sclerotherapy in cirrhosis. Gut 1985; 26: 421-5.

3 Burroughs AK, Jenkins WJ, Sherlock S, et al. Controlled trial of propranolol for the prevention of recurrent variceal hemorrhage in patients with cirrhosis. N Engl J Med 1983; 309: 1539-42.

4 Mills PR, Rae AP, Farah DA, Russell RI, Lorimer AR, Carter DC. Comparison of three adrenoreceptor blocking agents in patients with cirrhosis and portal hypertension. Gut 1984; 25: 73-8.

5 Hillon P, Lebrec D, Munoz C, Jungers M, Goldfarb G, Benhamou J-P. Comparison of the effects of a cardioselective and non-selective beta blocker on portal hypertension in patients with cirrhosis. Hepatology 1982; 2: 528-31.

6 Proctor E, Chatamra K. Controlled induction of cirrhosis in the rat. Br J Exp Pathol 1983; 64: 320-30.

7 Testas P, Chollet JM, Lautard M, et al. La cirrhose du rat au dimethylnitrosamine. J Chir 1981; 118: 261-8.

8 Jenkins SA, Grandison A, Baxter JN, Day DW, Taylor I, Shields S. A dimethylnitrosamine - induced model of cirrhosis and portal hypertension in the rat. J Hepatology 1985; 1: 489-99.

9 Van Thiel DH, Gavaler JS, Sloane FL, et al. Is feminization in alcoholic men due in part to portal hypertension: A rat model. Gastroenterology 1980: 78: 81-91.

10 Karran SJ, Eagles CJ, Fleming JS, Ackery DM. In vivo measurement of liver perfusion in the normal and partially hepatectomized rat using Tc- $99 \mathrm{~m}$ sulfur colloid. J Nucl Med 1979; 20: 26-31.

11 Fleming JS, Humphries NLM, Karran SJ, Goddard BA, Ackery DM. In vivo assessment of hepatic arterial and portal venous components of liver perfusion. $\mathrm{J} \mathrm{Nucl} \mathrm{Med}$ 1981; 22: 18-21.

12 Lee HB, Blaufox MD. Blood volume in the rat. $J$ Nucl Med 1985; 22: 72-6.

13 Fan FC, Schuessler GB, Chen RYZ, Chien S. Determinations of blood flow and shunting of 9 and $15 p$ microspheres in regional beds. Am J Physiol 1979; 237: H25-33.

14 Millward-Sadler GH, Hahn EG, Wright R. In: Wright R, Millward-Sadler H, Alberti KG, Karran SJ, eds. Liver and biliary disease. London: Saunders, 1986: 821-53.

15 Waxman AD. Scintigraphic evaluation of diffuse liver disease. Sem Nucl Med. 1982; 12: 75-88. 